"Batagelje"al" — 2009/2/18 — 23:19 — page 267 — \#1

\title{
CALIBRATE and CAS/DGS resources
}

\author{
Vladimir Batagelu, Iztok Kavkler and Matija Lokar
}

Abstract. The CALIBRATE project was initiated by the EU with the goal of expanding the use of ICT in education by increasing the amount of available learning resources via resource exchange. Although CAS/DGS can be used to easily create high quality learning resources which are also easily adaptable across national boundaries, such resources are difficult to find at CALIBRATE portals. We believe that this is due to CAS/DGS still being rather exotic to most of the people as well as with the common problem of finding existing appropriate resources. A possible solution is for CALIBRATE portals to properly equip existing and forthcoming CAS/DGS resources with suitable metadata and to provide some integration with CAS/DGS tools, enabling both beginners and power users to create and exchange CAS/DGS resources.

Key words and phrases: CAS/DGS educational resource, repository, metadata, brokerage, collaboration.

ZDM Subject Classification: B10, R20, U70, N80.

\section{Introduction}

The use of the information and communication technologies (ICT) in education process is not as spread as we could expect it to be. One of the reasons for this

The work presented in this paper is partially supported by the European Commission under the Information Society Technologies (IST) program of the 6th FP for RTD - as part of the CALIBRATE project, contract IST-28025. The authors are solely responsible for the content of this paper. It does not represent the opinion of the European Commission, and the European Commission is not responsible for any use that might be made of data appearing therein.

Copyright (c) 2008 by University of Debrecen 


$$
\text { "Batagelje'al" — 2009/2/18 — 23:19 — page 268 — \#2 }
$$

is a constant problem of finding appropriate learning resources to be used in the classroom, despite the fact that there are numerous learning resources available on the World Wide Web. The CALIBRATE project (6th Framework Project) is intended to support the collaborative use and exchange of learning resources in schools and thus overcome the problems of accessing appropriate resources. It should support the interoperability and adaptability of the Learning Resources on the European scale.

The CALIBRATE (Calibrating eLearning in Schools) [4] project brings together eight European countries to carry out a multi-level project designed to support the collaborative use and exchange of learning resources in schools. Its main aim is to provide brokerage system among national repositories of educational materials.

As a part of the project CALIBRATE we connected Slovenian Educational Network (SIO) [12] to the brokerage system [1]. Quite substantial amount of electronic teaching resources obtainable through SIO are various worksheets based on Computer Algebra Systems (CAS) or Computer Dynamic Geometry Systems (DGS). In math education, CAS/DGS can be used to produce this kind of resources without forcing the author to master difficult tools outside of her field. A survey, conducted within teachers' groups, has shown that teachers do not use enough of the resources made available. Nevertheless they claim they need suitable teaching resources in order to be able to incorporate information technology into their teaching process. The quality of electronic teaching materials (ETM), the problems with distribution of the materials, too demanding ways of modifying them, and lack of proper classification are only some of the most often mentioned as being the most important reasons for giving up or stopping the usage.

The possibility of modifying ETM is one of the properties ETM most often lack and math teachers demand. An important fact is that materials must have the possibility to be changed and adapted not just to the teacher's own teaching style but also to the whole concept where materials are used like age of students, previous knowledge, cultural differences - if we only mention few. Math teachers do not like using close form solutions; they want to be in control of the whole process. Simple and not too comprehensive ETMs are found most valuable.

In the paper we shall present the main goals of CALIBRATE project and discuss some problems in adapting educational resources for international use. We will discuss how CAS/DGS can benefit CALIBRATE and what, in turn, CALIBRATE can do to help more teachers and resource authors learn about these tools.
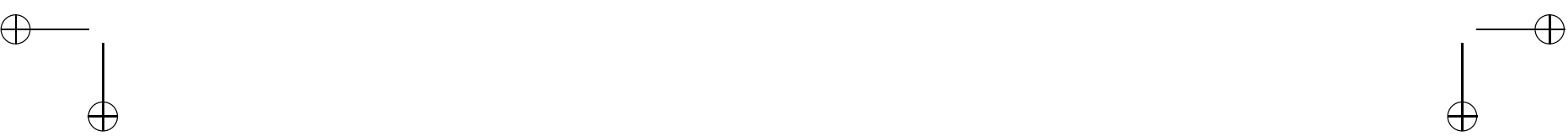


$$
\text { "Batagelj"eal" — 2009/2/18 — 23:19 — page 269 — \#3 }
$$

\section{About the project}

CALIBRATE is a 6th Framework project led by European Schoolnet (EUN). With support from the European Commission's Information Society Technologies (IST) Programme, the project is expected to develop a European Learning Resource Exchange for teachers and pupils. The work builds on the results of three previous IST projects (CELEBRATE, ITCOLE and VALNET). The CELEBRATE (Context eLearning with Broadband Technologies) pilot project [5] from the 5th Framework Program has demonstrated that although teachers are willing to use learning materials from the WWW, this usage is seriously limited by the fact that not enough such materials are available; in particular, not enough areas are covered.

The main goal of the CALIBRATE was to alleviate this shortcoming: to make enough of the resources available and easily accessible to teachers. For this purpose, the project brought together the ministries of education from eight EU member states: Austria, Belgium, Czech Republic, Estonia, Hungary, Lithuania, Poland and Slovenia, each with their own repository of learning materials. Six of the participating countries are new EU member states, a conscious decision with the goal to promote educational uses of ICT in the enlarged Europe.

The CALIBRATE project started in October 2005 and will be running until March 2008.

\section{Main goals of the project CALIBRATE}

The idea behind this project is quite simple even if the underlying technology is quite advanced. Essentially, the project will create a network or federation of learning content repositories. The network will allow teachers and pupils to freely access both learning resources and learning assets (images, simple text files, audio clips etc.) that can be used in the classroom. The search for these assets should be performed in a way teachers are already familiar with and in their own language. Technology behind will take care of producing and federating appropriate searches through participating repositories.

CALIBRATE has set itself several different goals, according to the most pressing needs established by the CELEBRATE project. Based on these goals, five work packages were formed. 


$$
\text { "Batagelje·al" — 2009/2/18 — 23:19 — page 270 — \#4 }
$$

\section{Classification of teaching resources}

The school programs in European countries differ significantly, but they mostly cover the same set of topics. For learning resources to be easily accessible there has to be a way to search for them based on the curriculum in every teacher's own country. The task of the first work package is to find the mappings between curricula in several states and create the taxonomy - a set of keywords, with unique mapping to every curriculum.

\section{Learning resource exchange (LRE)}

As mentioned before, the initial availability of resources is crucial for the success of the project. Since most countries already have their own repositories of learning materials, the natural step is to bring them all together. Most learning resources are accompanied with metadata, which contains a description and data intended to simplify searching. The goal of the LRE is to enable the exchange of this metadata. For this purpose, an international standard format LOM (learning object metadata) is used; it has been adapted in several minor points to better fit the needs of LRE. The metadata in the repositories are generally not stored in the LOM format. Therefore, every participating country has to provide an interface for searching and converting its metadata to LOM. The EUN office provides the central brokerage system, needed federated search through all the national repositories, as well as a basic software support to simplify the connection to the brokerage system.

Initial goal was to have all the metadata available in English. Unfortunately, this is generally not the case. There are other projects (e.g. MELT - Metadata Ecology for Learning and Teaching [10]) with the specific goal of enriching the metadata and providing English translations.

\section{LeMill: toolbox for adapting and producing teaching resources}

To help teachers adapt the learning material to the specific needs of the class and share the adapted content with others, a web based authoring system named LeMill [8]) is being developed. Design and adaptation of learning objects in LeMill is based on the cooperative model of work: the materials are stored on the web server and every update is instantly available to the whole community. All the resources in the LeMill are covered by the Creative Commons share-alike license [2], which fits such purposes very well. One of the problems that arose is the 
"Batagelje'al" — 2009/2/18 - 23:19 — page 271 — \#5

import of resources from national repositories to LeMill. It is an important part of the CALIBRATE integration, but it requires the imported resources to carry the same $\mathrm{CC}$ license which is often not the case in the national repositories (they are mostly older than CC licenses).

Apart from that, the cooperative model has several advantages, especially considering the international aspects of CALIBRATE. A suggested common scenario is the following: a Slovene teacher finds a resource in the Hungarian repository using the federated search. Based on the description (hopefully in English) in the metadata, she decides that she could use it for his classes. If the resource carries the CC-SA license, she can import it into LeMill. She connects with a Hungarian teacher from the LeMill community with a plea to translate the resource from Hungarian to a language they are both familiar with. As the last step, she translates it to Slovene and adapts it for the Slovene curriculum. The next time, the situation is reversed - so everybody wins. As a side effect, the quantity of content available in mediatory languages (e.g. English) grows, so no work needs to be duplicated the next time.

\section{Evaluation}

The evaluation of the project by a test group of teachers is important partly to understand the strong and the weak points of our approach, but even more to create the strategy on how to disseminate the finished product to as wide group of teachers as possible. The evaluation is running in 20 schools in four states. A set of expertly prepared questionnaires will be used to judge the results.

\section{Dissemination}

The goal of the project is not only to produce the tools, but also to educate the teachers on how to use them and how to create new ones. We hope to reach the "critical mass" of teachers, which will enable the further use to spread on its own.

\section{Finding educational teaching resources}

There is a substantial amount of math teaching and learning resources obtainable through the net. Sites like:

- http://www.mathcentre.ac.uk 
- http://planetmath.org

- http://www.e-um.si/

- http://www.matheprisma.de

- http://www . math.com

- http://www . mathe-online.at

are just few examples of various portals where educational math teaching resources can be found. Simple search on Google with keywords math, teaching, resources gives more than 6.5 million hits. But a survey, conducted in 2005 within Slovene teachers' groups, has shown that teachers do not use enough of the resources made available. Especially math teachers were "slow to adopt" such materials as a survey [6] showed, somehow a surprising fact. Namely, math teachers were among the first followers of the home computers (Spectrum ZX, Commodore 64) as a teaching tools boom in the eighties. It can be seen from Figure 1 (data from [6]) quite impressive one third teachers used computers in their teaching work in late eighties.

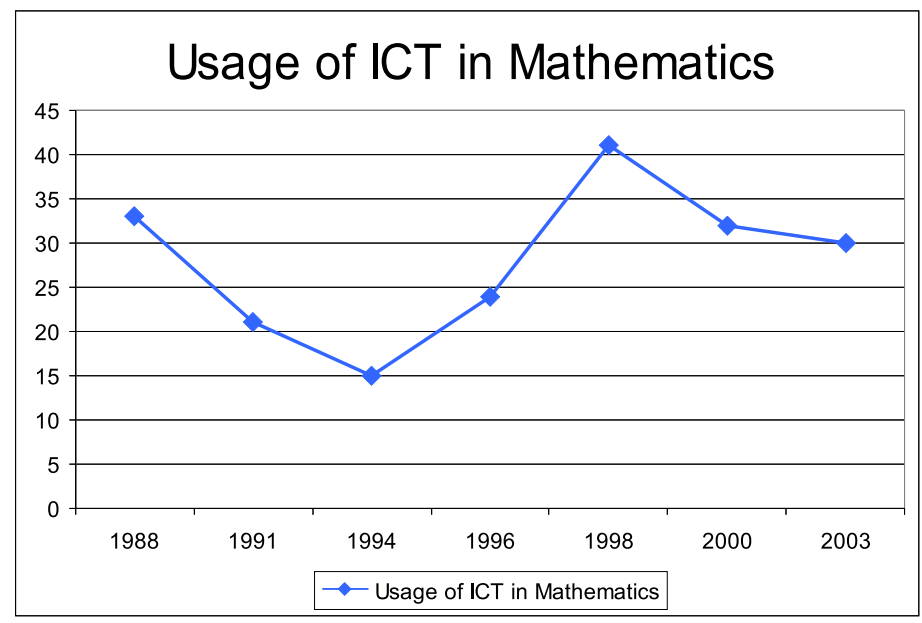

Figure 1. Usage of ICT Tools in teaching of mathematics

Teachers claim that the main reason for not using teaching resources is that they need suitable teaching resources in order to be able to incorporate information technology into their teaching process - the fact that lead to the first drop of usage that can be observed in Figure 1 where the lack of suitable resources due 
"Batagelje'al" — 2009/2/18 — 23:19 — page 273 — \#7

to the change of technology (introduction of PCs instead of home computers and emergence of Windows operating system) really lead to significant drop of usage.

But the second drop in 1998 has a completely different reason and this one can be connected to the present situation. Namely, the observation of active usage of e-materials in the teachers' work has shown that access to a large number of e-materials (mostly due to organizing the Slovenian portal (SIO) with links to various educational resources in 1995) after the (expected) initial boom actually led to the reduction of their use in teaching.

Interviews with teachers showed several reasons that led to the observed decline in usage. The quality of electronic teaching materials [3], the problems with distribution of the materials, too demanding ways of modifying them, and lack of proper classification are only some of the most often mentioned as being the most important reasons for giving up or stopping the usage [7].

Unfortunately, using and preparing suitable teaching materials in Slovenia is quite demanding. A small population ( 2 million) and the obligation to use only native language materials in schools make a small market as well as limit the number of potential authors.

Apparently we have an overwhelming amount of math teaching resources in other languages and lack of the suitable ones in Slovene language [9]. Problems with the quality suggest the use of national repositories with quality control. However, this means a significant drop of available resources all over Europe. An obvious remedy is to connect repositories and search through all of them. But as soon as we try to reduce the number of possible hits we encounter problems with proper keywords, different age settings in different school systems across Europe... The reasons for CALIBRATE project were obvious.

\section{Classification and metadata}

The main goal of the CALIBRATE project is to help teachers find and use the teaching materials, not only from their own country's repositories, but from all over Europe.

The first question that usually arises is: why use CALIBRATE, not Google? Almost all resources available are probably already indexed by Google. Yes, they are, but it is difficult for a text search engine to differentiate between a teaching resource about "linear function" and an article that just happens to mention "linear function" in the context of, say, economy. Then there is the language issue standard search engines find mainly English resources provided that the query is 


$$
\text { "Batagelje'al" — 2009/2/18 — 23:19 — page 274 — \#8 }
$$

in English. How about finding an Estonian resource with a Slovene query? In educational repositories the metadata are augmented with educational information, with quality evaluations, with copyright information ... all of which can make the search much more "educationally oriented". Google's indexer doesn't care about this kind of information.

CALIBRATE helps with these issues by using metadata along with the resource. Metadata is standardized in a way that enables the search throughout the federation: a simple description (possibly in multiple languages), language neutral keywords (defined by an international thesaurus), the approximate age at which the subject is taught (instead of school level, which seems to be much more country dependent).... A lot of metadata already exists in the national repositories and the missing pieces are being added by other projects, like Melt.

CALIBRATE also guarantees the suitability of materials for teaching. All partners have agreed to provide some quality control through their ministries of education.

An idea that seems to have even more potential is the idea of curriculum mapping. It is still far from finished, but when it works, a teacher will be able to click on today's lecture in her school program and obtain all resources throughout Europe that deal with that.

With mechanisms described above implemented in portals the teacher can search through the repositories in his own language, but how does he solve the language problem - the results she obtains are in the best case in English, but mostly in a language she doesn't speak a word of? As for metadata, as much as possible should be at least bilingual - native language and English. Moreover, automatic translators for metadata are being built. Of course, automatic translation never produces perfect results, but it may be enough for the teacher to understand what the resource is about.

And what can we do about the language of the resource itself? The resource certainly needs to be translated by a human. We hope the community process as described in the paragraph about LeMill will help here. In the future, solutions based on controlled languages (see [11] for example) could find their place in the development of learning materials. 
"Batagelje'al" — 2009/2/18 — 23:19 — page 275 — \#9

\section{Adapting educational teaching resources}

One of the important research results of the evaluation phase is that dominantly text resources don't fit very well with the needs of CALIBRATE. There are several reasons for that:

1. These resources don't "travel well" - they have to be translated to every language to be of any use and the amount of work needed for translation is in many cases nearly equal to the amount of work needed to create the resource in the first place.

2. Teachers have pointed out that the most important benefit they expect from the use of ICT is a way to motivate the pupils - and a text page is no more interesting than a schoolbook.

3. Substantional amount of school topics is already well covered by Wikipedia, so most teachers will first look there for textual content (and it is already in English, so LRE hardly competes). Note that this is mostly true for expository texts; textual exercises are very useful to teachers as they relieve them from reinventing the exercises for every class.

What are the resources that best fit the philosophy of CALIBRATE? Well known examples are short movies, simulated experiments and interactive exercises - they don't contain much text to translate and have good motivating effect. Moreover, interactive exercises provide instant feedback, giving the pupil better opportunity to learn from his own mistakes while relieving the teacher of the tedious task of correcting.

In the fields of mathematics, physics and chemistry (but also others, like grammar) CAS/DGS tools are the perfect equipment for creating the good kind of content. CAS are perfect for producing interactive exercises while DGS are exactly the tools you need for presenting the geometric constructions and experimental schemes with visible time component (which is sorely missing from the drawings in books).

Considering these advantages, the LRE repositories should be full of interactive CAS/DGS content. But are they? Well no, not really. There are some 
exercises produced by CAS and later packaged as SCORM ${ }^{1}$ and some geometric presentations are produced by DGS (surprisingly few, considering how much easier it is to work with a DGS than with a traditional drawing program).

What is the reason? For one, many content creators don't know about these tools or they can't use them. CALIBRATE can certainly help here. Simply adding a source package and a link to program, with which it was created, will help people who want to adapt the resource or create something similar. This could become an official guideline.

Another problem is the poor ability to exchange content. The materials in CALIBRATE must work on different computers in different countries and different languages. The teacher has to be able to cut them, translate them and adapt them to this year's curriculum and today's lecture.

CAS/DGS fare rather badly in this respect: every program uses its own, proprietary format. It's true that many CAS can export some open format like HTML, SCORM or simply animated GIF - but although the exported data can perhaps be translated with a plain text editor, it has lost most of its adaptability. Neither of these formats comes close to representing the semantics of a CAS/DGS.

As an exception to above, some of the most valuable assets regarding teaching resources are various worksheets - either produced by CAS or tutoring pupils to use CAS. Exchange of such materials, discoverable through LRE mechanisms and adapted/translated with the help of tools like LeMill provides, could boost the use of CAS materials.

For the rest, the obvious solution would be to agree on the standard CAS system or at least on a standard exchange format for CAS resources. We believe that neither is likely to happen (in the near future). Agreeing on a standard program is difficult because every successful one covers some area better than others. Moreover, any two CAS programs seem to be based on different philosophies; finding the lowest common denominator is next to impossible.

Standard exchange format seems similarly unfeasible, since every CAS is based on a complicated symbolic computation language with its own semantics. For this reason, the exchange format would have to be based on a low level

${ }^{1} \mathrm{SCORM}$ is a standardized format for packaging and sequencing interactive learning resources. Technically, a SCORM packet is a zip file containing one or multiple web resources and corresponding metadata (a variant of LOM). SCORM supports standard means of communication between the packet and the containing LMS environment: the packet can return information about the time a student has spent reading the resource, about marks achieved in quizzes and whether the resource workflow has been completed. The downside of SCORM is that it is rather difficult to change and repurpose an existing packet. 
representation of data, again losing most of the information important to the creator. Besides, even if the common format is agreed upon, it would take years before every user obtains a version of her favorite program that supports it.

\section{Using metadata to circumvent the problems of program diversity}

If neither of the above options is realistic, what can we do to accelerate the exchange of the CAS/DGS content? As creators of the repositories and learning portals we have an option that fits well with the CALIBRATE's metadata based approach. In LOM there are some fields dedicated to the technical aspects of the learning resource - the program(s) with which it was created, the platform on which it runs, even the instructions for installation can be put in there. So far this information wasn't very useful as most resources were HTML pages, pictures or movies. For this reason, it's either not present or is unreliable in most metadata records.

However, this kind of information can be used to (in part) solve the "program diversity" problems of CAS/DGS. Namely, it provides the learning resource portal with a number of opportunities to simplify discovery and modification of CAS/DGS created resources.

1. When a resource is found, the portal can offer the teacher instructions on how to open it.

2. Resources can be searched for according to the program, with which they were created, allowing people to use and adapt resources with their favorite tools.

3. The portal can automatically create a page that enumerates the CAS/DGS programs and links them to the corresponding resources. This page can be sorted by the popularity, stimulating the users, fresh to CAS/DGS, to try some of the more popular programs.

4. The power users could create tutorials for popular programs. Links to these tutorials can be added to the index page, helping beginners embrace these tools.

5. Teachers using the same program will have an opportunity to meet each other, creating communities of content creators using CAS/DGS. The resulting exchange of ideas should significantly improve content creation. 
Even when the metadata is unreliable, the repository could augment it with the automatically gathered metadata based on the resource type (which can be quite reliably established from the file name and the file data). For this purpose, some canonical metadata for each program must be identified (possibly by the administrator of the repository).

Of course, there are difficulties that this approach cannot solve. Sometimes a resource requires a program that a teacher cannot use. Perhaps it is not available to her - some of these programs are quite expensive - or it requires too much effort to learn how to use a new tool. The second problem can be solved by some community help or the abovementioned tutorials. As for the first problem, the free tools are becoming more popular in the recent years and even the commercial ones usually offer at least free viewers.

\section{Conclusion}

CALIBRATE should have positive impact on CAS/DGS usage in teaching process. It will provide technical means to easily connect different repositories. Teachers and other users will be exposed to much more appropriate teaching and learning assets, ideas for creation of new ones and community help "when things go wrong". Through promoting open source licensing and adaptability of learning resources the community of teachers, using suitable CAS/DGS resources will also grow. The results of the CALIBRATE project should demonstrate the often neglected fact that metadata is useful if we want to discover appropriate resources through internet. Community oriented tools and ideas like those developed and promoted in LeMill could also help to promote appropriate use of CAS/CDGM in the teaching process.

On the other hand, the "use your favorite tool" idea from the previous section, while almost essential for the adoption of CALIBRATE by CAS/DGS users, could have beneficial effects for the whole CALIBRATE project. Tools like LeMill (or some LMS system) are good for compiling learning objects into ready-for-use resources and for resource translation, but their abilities rarely go beyond simple HTML editing (or perhaps creating a quiz). For serious authoring of multimedia and interactive objects, specialized tools have to be used. Better integration of CALIBRATE and LeMill with this kind of tools would speed up resource creation/modification and make the jump from a simple content user/adaptor to a content creator much less intimidating. 


\section{References}

[1] V. Batagelj and I. Kavkler, CALIBRATE and the new Trubar, in: Proceedings of the International Conference Enabling Education and Research with ICT, Arnes, Ljubljana, 2007.

[2] CreativeCommons, http://creativecommons.org/.

[3] D. Dinevski, J. Jakončič-Faganel, M. Lokar and B. Žnidaršič, Quality assessment of electronic learning material, in: KMO'2006: knowledge management in organizations: proceedings of the First International Conference for New Trends in Knowledge Management, (M. Heričko and A. Živkovič, eds.), Faculty of Electrical Engineering and Computer Science, Institute of informatics, Maribor, 2006.

[4] EU Project CALIBRATE - Calibrating eLearning in Schools, http://calibrate. eun.org/ww/en/pub/calibrate_project/home_page.htm.

[5] EU Project CELEBRATE - Context eLearning with Broadband Technologies, http://celebrate.eun.org/eun.org2/eun/en/index_celebrate.cfm.

[6] I. Gerlič, Stanje in trendi uporabe računalnika v slovenskih osnovnih in srednjih šolah - raziskovalno poročilo, 2003 (in Slovene), http: //www.ris .org/main/baza/baza.php?bid=295.

[7] J. Jakončič-Faganel and M. Lokar, Quality of electronic materials for math teaching, in: Proceedings of the 3rd International Conference on the Teaching of Mathematics at the Undergraduate Level, John Wiley \& Sons, Istanbul, 2006.

[8] LeMill, http://lemill.org/trac/ \& http://lemill.net/content/overview-of-lemill.

[9] M. Lokar, Electronic teaching and learning resources in math teaching in Slovenia, in: Proceedings of the 3rd International Conference on the Teaching of Mathematics at the Undergraduate Level, John Wiley \& Sons, Istanbul, 2006.

[10] MELT - EU Project Metadata Ecology for Learning and Teaching, http://info.melt-project.eu/ww/en/pub/melt_project/about.htm.

[11] T. Mitamura, Controlled language for multilingual machine translation, 1999, http://www.lti.cs.cmu.edu/Research/Kant/PDF/MTSummit99.pdf.

[12] Slovensko izobraževalno omrežje - Slovenian Educational Network, http://sio.edus.si.

VLADIMIR BATAGELJ, IZTOK KAVKLER and MATIJA LOKAR

FACULTY OF MATHEMATICS AND PHYSICS

UNIVERSITY OF LJUBLJANA

JADRANSKA 19, 1000 LJUBLJANA, SLOVENIJA

E-mail: vladimir.batagelj@fmf.uni-lj.si

E-mail: iztok.kavkler@fmf.uni-lj.si

E-mail: matija.lokar@fmf.uni-lj.si

(Received September, 2007)

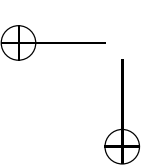

